\title{
Relinquishing the Practices of a Lifetime: Observations on ageing, caring and literacies
}

\author{
MARY HAMILTON
}

\begin{abstract}
This paper draws on ethnographic and case study data from a variety of sources to explore the changing social practices of literacy across the lifespan. It explores the new literacy demands that people encounter with age when dealing with life events in a range of social domains. These include increased leisure; travel; changing family and peer relationships as a result of death and loss; issues of health and disability and accessing new technologies. It reveals how literacy is implicated in peoples' changing sense of time, place and history; how the older person's identity as a literate actor may be interrupted by both institutional and informal processes of caring and their disengagement from spheres of activity that were previously central markers of their identity. Ageing thus involves both expansion and retreat from familiar literacy practices.
\end{abstract}

\section{Introduction}

Older adults are one significant group who have been defined as being 'outside' of contemporary literacy policy because they are not seen to be relevant to goals of economic productivity. This is despite the fact that populations of post-industrial societies are becoming progressively older and that adults' literacy skills - when measured in cross-sectional surveys - appear to decline systematically with age (see, for example Weinstein-Shr 1995, OECD 2000). What consequences do literacy changes across the lifespan have for individuals and societies? What are the implications for policies and programs serving older adults? In what ways do the measured differences in literacy skills correspond with changes in the literacy practices of adults as they become older?

This paper draws on ethnographic and case study data from a variety of sources to explore the changing social practices of literacy across the lifespan. It illustrates some of the new literacy demands that people encounter with age in the legal and financial domains, in dealing with life events linked with changing family and peer relationships; death and loss; increased leisure; travel; and new technologies. It reveals how literacy is implicated in people's changing sense of time, place and history; how the older person's identity as a literate actor may be interrupted by the processes of caring and their disengagement from spheres of activity that were 
previously central markers of their identity. It suggests that ageing thus involves both expansion and retreat from familiar literacy practices.

Some key issues in the field of literacy studies are thrown into new relief when examined through the lens of ageing. These include the role of literacy in relations of interdependency and mediation, especially the delicate balances of inter-generational support and control, negotiating the boundaries of public and private knowledge, and the importance of considering trust, fear and respect as factors in supporting literacy practices among older people that are acceptable to them.

\section{Picturing literacy and ageing from above and below}

Explanations in the survey literature of declining literacy performance with age are typically couched in terms of cognitive change in functioning or changing educational opportunity over the last century. Factors such as disuse of skills, or disinclination to learn in old age are cited (see Weinstein-Shr 1995). Whilst these factors are undoubtedly part of the picture, my aim is to examine what additional insights into the relationship between literacy and seniority can be gained from applying a social practice perspective.

The features of the social practice approach to literacy studies have already been rehearsed in general terms in the introduction to this volume by Sondra Cuban. For the purposes of this paper it is important to note that this approach aims to present literacy and ageing from the perspective of those experiencing it directly using a detailed, ethnographic method and focusing on the dynamics of individual subjects within a complex of contextual factors. Such studies differ from traditional surveys of need in focusing not just on the deficits of those with few formal educational achievements. Highly educated adults who have made their mark on life also experience change and have to re-negotiate the risks and positive benefits of literacy in older life. The ways in which they do so are just as important to explore if we are interested in understanding textually mediated social worlds.

A social practice approach can usefully document three identity-related aspects of literacy: 1) older peoples' subjective experiences of literacy, 2) the changing social networks and affiliations that are significant to older people, and 3) the ways in which older people are positioned by their literacymediated encounters with individuals and with social institutions. Such data can offer rich accounts of subjectivities and the social meanings of literacy.

This social practice approach forces us to take account of aspects of literacy experience other than the purely cognitive. A focus on ageing leads inevitably to consideration of embodied practices and the changing materialities of how a person, as a subject, engages with literacy. This is not just a result of the changing materialities of literacy technologies, a theme that is already well explored in the literature (see for example Snyder 1997, Kress 2003) but the changing materiality of the subjects themselves in sometimes 
rapid and extraordinary ways due to changes in memory, sensory changes in sight and hearing, joint stiffness, lack of mobility, strength and energy. There are positives, too, in embodied experience: a different sense of time and pace; the availability of more, slower, time; and a breadth of emotional experience and understanding built over the lifespan and invested in particular literacy practices and artefacts. These positive aspects are often drawn on as resources by other people involved in the networks and organizations in which older people participate. As Janet Isserlis puts it:

elderly people have made spaces in the world, have interacted with people and events that many of us, who are younger, may be familiar with or not but have not experienced in the way that someone who was alive before the advent of television, the internet, fruit leather or space exploration might. Older people know things that young people don't know and they know things differently (Isserlis 2003).

\section{Data}

This paper draws on existing ethnographic and interview case study data from a variety of sources to identify a set of themes suggested by the social practice perspective. It is a speculative first exploration of this topic and the data has mostly been generated in studies that have aimed to document literacy practices more generally. Few of these studies have focused specifically on ageing but they have picked up relevant material incidentally by looking at textually mediated lives in a range of settings and conditions. Obviously, the details and literacy practices of older people will differ considerably under different social, cultural, economic, political and geographic conditions. The studies I quote from do not represent an even geographical spread and there is an emphasis on the UK and my own locality in the North West of England. However, my assumption is that the conceptual framework of literacy practices and the elements and processes identified through it can usefully be applied to the experience of older people in other contexts. The studies I have drawn on for this paper include Local Literacies (Barton and Hamilton, 1998, based in Lancaster England), Changing Faces (Hamilton and Hillier 2006, based on a national English sample), and practitioner research projects (e.g. Milioti 2000, Isserlis, 2003 both from North America). Some quotations are also drawn from a collaborative study of Changing Literacies and Changing Technologies across the Lifespan' currently being carried out with a group of Senior Learners at Lancaster University, England (referred to in this paper as the 'Senior Learners Project'). This project and the present paper are preliminary steps toward more systematic study. 


\section{Literacy practices expand with age}

This section discusses the expansions of literacy that take place in old age as a result of the accumulated experience and mastery of a lifetime. These expansions result from the sense of time and place that many people arrive at or strive for in old age, a sense of history that is at once both individual and collective and which draws on reservoirs of cultural and linguistic knowledge. This can be seen clearly in the example of family history. Documenting family trees and crafting stories related to family history that can be passed onto new generations is a common interest among older people. The status and identity that come from being the eldest in a family or community network is constantly refocused as friends and relatives die, people move into new roles and intergenerational dynamics change. There is never total closure or certainty, rather a degree of flexibility is always present, and literacy practices and interests shift accordingly.

Harry (see Barton and Hamilton 1998:81) was 66 years of age, a younger elder, when we met him as part of the Local Literacies project. He was already a grandfather, retired from the fire service and interested in writing his life history, especially his memoirs from the war. He was a man who had learned his literacies in his adult life through his work, his networks and interests, and he held a respected place in the local community. Despite his lack of formal education, he was frequently asked for advice and to write references, he wrote letters to the local paper and used the library regularly. He was an officer in several local community groups.

Although we did not treat Harry particularly as an 'old man' in our analysis there are several aspects of his literacy practices that seem, with hindsight, to be age related. He told stories of the limited educational opportunities that left him aware of the greater formal proficiencies of his own children and grandchildren. Such stories are typical of his generational cohort (see Antikainen et al 1996), Field and Malcolm 2005, but there is also something more general to notice about the ways that he was using his writing and reading to make sense of a life that he can already look back on and draw lessons from, for himself and for others. Whilst his wife was still alive, Harry, like many other people had already begun to document his family history, using written artefacts and a range of other media: collecting books, photos and family records; looking up names in church record books; and accompanying his wife on visits to cemeteries and libraries.

The advent of the internet has made visible the extent of such ancestor hunting activities. In the UK, the extent of interest with genealogy first became clear in 2002 when the data from the 1901 census was posted online. The website was overwhelmed, crashing under the weight of 30 million hits a day as people looked up their ancestors (Rudd 2008). This passion, utilised in reminiscence work in literacy programs and reflected in the popularity of 
local and family history adult education, may not be equally shared across social groups. I would suggest that it may be identified particularly with older adults and has special appeal to those who have been displaced from their familiar cultural context, not just by time, but through war, economic migration and so on. Younger people may also engage in family history activities in the context of intergenerational exchange as found in one example drawn from the Senior Learners Project. Inspired by the 2006 Football World Cup, 84 year old Roy's grandson helped his grandfather research and assemble documents about his great grandfather who was a one of the first professional footballers and trainers in England. Between them, they collected a mixture of family photographs, old programs, newspaper cuttings and internet information.

\section{Literacy in different domains of older life}

The example of family history is one domain where literacy expands with age and raises a set of interesting questions about sense-making and identity that can then be asked of younger and other social groups. The following section looks at several more key domains in which both expansions of, and withdrawal from literacy-related activities occur. It looks in turn at leisure, financial matters, use of the mass media and new technologies, and finally at the domain of caring which leads into a consideration of institutional responses to older people.

\section{Leisure}

Old age often brings substantial continuities with earlier interests, activities and expertise, though some domains, such as legal, financial and health, may become ever more salient and generative. For some people community-based networking and local political activities such as lobbying, organizing or serving on committees become more central as time is freed up from other commitments. Other activities (such as those related to employment, participation in rock music festivals or extreme sports) may recede, although many people maintain spectator links with these via social networks and the mass media. In the Senior Learners project, the importance of music - recording and listening to it - was one of the first domains to emerge in discussions about new technologies. In the Local Literacies project, Cliff Holt and his step-sister, Rose searched out a variety of local entertainment and leisure activities within the constraints of their very limited budgets. About six months before we interviewed them, they had developed a common interest in horse racing and betting and explained in detail their attempts to get to grips with the practices associated with placing bets. These included looking at newspapers, tote books, betting slips, the 'tick-tack' signaling system used on the race course and information on television and computer monitors (Barton and Hamilton 1998:140). 


\section{Financial Matters}

New literacy-related demands in legal and financial domains are faced by many older people when they deal with events such as death, loss and managing property and inheritance. Older people act as sponsors and executors for others, as well as rearranging their own affairs with a view to dispersing rather than accumulating assets that is an earlier life preoccupation. In Janet Isserlis's portrait of her aunt Lil (2003), despite failing faculties and energy Lil remained, almost to the moment of her death, concerned about, and connected to, ensuring that her papers were in order. She remembered, for example, a cheque that she needed to write for a relative, maintaining well organized records and procedures for carrying this out. She adapted these procedures to incorporate an increasing degree of collaboration with others, reducing the burden of literacy that she needed to carry herself.

Early in the afternoon of my birthday, she had my mother write the date, my name, the figure and words: Lil then signed the cheque. I was struck by how dramatically Lil's signature had changed; the letters were scribbly; her usual characteristic writing had visibly changed. I no longer remember how much, if any, writing she'd done during her last month in hospital. I don't think she did much, beyond, maybe, circling items on a daily menu...I do know (or think I know) that during her last few weeks, she'd lost interest in reading. I think she found it exhausting after having been an avid reader for as long as I'd known her (Isserlis, 2003).

\section{Mobility and Media}

Old age may bring either expansion of, or withdrawal from, the domain of travel and mobility, depending on circumstances. Expansion may occur due to increased time, eligibility for discounted services and sometimes available money after retirement. For many, however, health and reduced financial resources place new restrictions on mobility that have to be accommodated. One result of this for many older people, especially those confined to the home or institutional care is the importance of the mass media as an information source, for entertainment and social connection. A recent report (Office of Communications 2007) found that older people in the UK access familiar rather than newer media and that hours of television watching are highest in the oldest age groups and among those with disabilities. Literacy may increase in importance as a mediator of social communication as face-to-face contact with others becomes more difficult to maintain. A common motivation for learning to use e-mail among participants in the Senior Learners Project was to communicate with distant 
relatives, especially children for whom this was the obvious way to keep in touch.

Living a life inevitably brings with it encounters with new technologies and it is well worth considering how older people approach new technologies in distinctly different ways from, for example, children and young adults. The most obvious aspect of this is the overlaying of new competencies on old, whether it is the change in a system of measurement or a currency that renders people effectively bi-numerate or the displacement of an old technology such as the typewriter or the postcard, with a replacement for the same task. These changes bring both advantages and disadvantages for the user and render some of their existing skills obsolete. In some cases the encounter with a new technology is a sudden experience in old age, but in many other instances it is part of a lifelong adaptation to change and we should not underestimate the resources people can bring to this process, the meta-level knowledge it generates and the flexibility with which new practices can be incorporated into daily routines. In this sense, the skilled literacy user is constantly relinquishing their established knowledge and practices in the pursuit of everyday goal. Pam recounts with humor learning to text from her daughter as, in part, having to learn to re-compose the wordy message she would normally write, to something shorter that can - is expected to be sent in an instant:

We went to H------ on Bank holiday Monday and on the way back I got a text and I was trying to send one back and she said 'mother are you writing a four page letter'? Because it was taking me that long she said 'give it to me, what do you want to say?' (Hamilton and Hillier 2006:53)

There are some interesting studies emerging of older people's incorporation of health technologies into their domestic routines, for example the use of alarm pendants (see Domenech and Lopez 2007) or hearing aids. A key dimension here is the identities that people build for themselves in relation to health risks. These determine how intimacy with a protective device develops as the device continually questions a person's existing view of their self-efficacy. A fit, but at risk, older person may not wish to identify with the information and images in a brochure showing someone like themselves in a dangerous position, for example after a fall. Intimacy with a protective alarm may paradoxically make them feel more at risk, less in control, rather than safer with the result that they 'lose' or reject the device. Where a device increases a sense of control and expertise, however, it may be actively incorporated into daily routines. An example of this from the Senior Learners Project was self-monitoring of blood pressure using a device that can be bought from the pharmacy. This enabled more frequent testing and a double check on information given by the doctor. These examples highlight 
how use and understanding of information about health artefacts - including drugs - is much more complex than simply whether people can read the instructions given out by a health professional.

\section{Caring}

The domain of caring, is one that is frequently highlighted in studies of older, adults. On the one hand, many older people become increasingly involved as carers themselves. Partly as a result of the ageing process itself, partly because in withdrawing from the world of paid public work, older people have time to give attention to younger generations. If they are physically able and close by, they may be closely involved as babysitters and in childcare more generally as Pam, the informant quoted earlier, describes as part of her reciprocal family relationships (see Hamilton and Hillier 2006:53). Many grandparents are primary carers of children (see Mission Australia 2007, Suarez 2007). On the other hand, as time goes on, many older people become increasingly dependent on others for their own personal care.

\section{Institutional positioning of older people}

The examples given in the previous section have touched on issues of identity and literacy and this becomes more important as we think about how the increasingly textualised world interacts with the experience of old age, benefiting some, marginalizing others. By moving from the world of employment into retirement, old age and pensions, many people find themselves, for the first time for many years, in contact with the state bureaucracies delivering caring and welfare services directly on their own account. Such agencies are, to use Deb Brandt's term, major sponsors of literacy in old age and they intrude into the privacy of domestic life (Brandt 2001). In data from the Senior Learners project, Roy smiles as he tells how the social worker came with an independent living assessment form with many questions to fill in. He submits to this because he feels entitled to some aids that are available free through the local council. 'She asked me if I had my own teeth and how often I clean them. I told her of course I had my own teeth, who else's would I have? But what did she need to know that for?' In fact, he has had dentures since the age of 23 but this piece of personal, intimate information is not given freely to someone he has never met before, sitting in his home with a clipboard.

Roy, like others of his generation, has also had to accommodate to changes in collecting his weekly pension from a system that required no writing (the post office cashier tore out the weekly voucher from a book, date stamping both the voucher and the remaining stub and handed over the cash) to one that uses a SMART card that requires memorizing a PIN and 
punching this into a machine quickly and accurately, in a public place, in order to obtain the money from his bank account.

In her account of her grandmother's move into a care home due to her deteriorating eyesight, Deana Milioti (2000) describes how this move interrupted both her grandmother's social networks and her established literacy practices which had enabled her to communicate with friends and family of all ages, to cook food, and to get news and information. In a noisy environment, with busy staff, surrounded by more needy patients than herself, the routines of the care home exacerbated her problems rather than mitigated them. Milioti (2000) observes the high reliance on oral communication with the patients whilst the organizational aspects of the care home, that co-ordinated the staff's actions (for example around medication and meal times) were largely written and not shared with patients. Care homes also tend to limit residents' access to communication technologies such as phones and computers.

\section{The mediating functions of family and community networks}

The institutional encounters with literacy described above often involve a three-way transaction between the older person, institutional staff and family carer. The role of the family carer may vary from that of onlooker to active intermediary and advocate. Many of the procedures and paperwork designed by caring agencies have to take account of this - respecting the autonomy of the older person yet their need for support by trusted others is reflected in the form-filling procedures demanded by medical and other services. A common example is a scene in the hospital outpatient's waiting room where the patient discusses and interprets with relatives the form that the doctor has asked them to fill-in and the implications of giving consent to a medical procedure.

Paperwork can become overwhelming or its significance is unrecognised. In one example, Robert's daughter discovers months of unpaid bills and correspondence in his study, left unopened. Though he has been a distinguished doctor and is a highly literate person, the paperwork entailed by these letters is too exhausting or uninteresting to engage him anymore. However, the example of a collaboratively written cheque in Janet Isserlis's case study of Lil illustrates the crucial power of the signature to the exercise of adult autonomy (as Mace 2002 argues). Giving power of attorney even to a well-known friend or family member is a most significant one to a person's sense of identity and control. The fear of fraud and deception can colour even apparently cordial family relations. Relinquishing the right to sign is symbolic of an identity shift from being an authoritative and autonomous member of the family and community as provider and carer of others, a writer and decision-maker, to that of being cared for. 
In the negotiation of these situations by elderly people and their friends, family and institutional care services, the necessary letting go of control reveals them to be complex, fraught with power relations. The site of old age thus highlights the emotional sensitivities of networks of interdependency, the importance of trust, fear, respect and the large amount of work that must be done to achieve a balance between support and control. The metaphor of social capital captures little of the texture of the subtle exchanges that constitute acceptable behaviors between consenting adults and these have been better explored in anthropological studies of reciprocity (Hyde 2006).

\section{Conclusions and implications}

To date, studies of literacy and ageing have tended to be prompted by the changing demographic of age and concerns for social inclusion among a group who had fewer opportunities for schooling than the current generation. These older people may now experience increasing isolation from the networks of friends and family that have sustained them across their lifespan. Whilst I share these interests and concerns, an ethnographic eye on the literacies of old age proves to be productive in its own right. It highlights domains, relationships, new questions and issues that we can take back into literacy studies more widely. In particular it focuses attention on the ways in which older people are repositioned by the institutional encounters that accompany changes of status and rites of passage such as retirement from paid work, becoming a grandparent, eligibility for services and pensions, or becoming formally defined as disabled. These encounters are often mediated by literacy. A fine-grained exploration of them underscores the complexity of exchanges within networks of support. Trust, intimacy, respect for autonomy; reciprocity and economic exchange; negotiation of the boundaries of public and private space - all these are significant dimensions of people's experience. The ethnographic eye also emphasises the dimensions of embodiment and materiality involved in resisting or managing changes in both the ageing human agent themselves and the technologies involved in communicating across the lifespan.

There are thus a number of lessons for policy that can be drawn from this paper. Firstly, a lifespan approach to literacies is important. There is a great deal of life after retirement and after the age of 50. Policy needs to differentiate more clearly among 'younger' and 'older' elderly. There is a need for cross-disciplinary policy responses and conversations, for example between education, health and social services. Secondly, we need to pay attention to the potential of the mass media and communicative resources as well as formal educational opportunities to enhance literacy use, new learning and autonomy among older people. Paradoxically, with decreased mobility older people have a higher reliance on the mass media and technological 
solutions to keep in touch with other people and the world at large. Third, we need better understanding of the complex mediating roles of family, peers and institutions (often all implicated at the same time) in negotiating and supporting changes in literacy practices over time. Intergenerational learning programs that span several generations, including grandparents as active participants, have great potential to promote age desegregation and understanding of these issues.

\section{References}

Antikainen, A, Houtsonen, J, Kauppila, J and Huotelin, H (1996) Living in a Learning Society: Life histories, identities and education, Falmer Press, London.

Barton, D and Hamilton, M (1998) Local Literacies: A study of reading and writing in one community, Routledge, London and New York.

Domenech, M and Lopez, D (2007) Older People and Artefacts: A problem of intimacy, Paper presented to the Centre for Science Studies and Institute for Health Research Seminar Series, Lancaster University, England.

Field, J and Malcolm, I (2005) Talking About My Generation: Learning, identity and agency - the role of historical time and generational time over the life course, Proceedings of the 3rd International Conference at CRLL (Centre for Research in Lifelong Learning), University of Stirling, 24-26 June 2005, vol 1, pp 168-174.

Hamilton, M and Hillier, Y (2006) The Changing Face of Adult Literacy, Language and Numeracy 1970-2000: A critical history, Trentham Books, Stoke on Trent, England.

Hyde, L (2006) The Gift, Canongate Books, Edinburgh, Scotland.

Isserlis, J (2003) Signing the Cheque: Case study of Lil's literacy practices, retrieved June 2008 from

http://www.brown.edu/Departments/Swearer_Center/Literacy_Resour ces/hamilton.isserlis.html

Kress, G (2003) Literacy in the New Media Age, Routledge, London.

Mace, J (2002) The Give and Take of Writing: Scribes, literacy and everyday life, NIACE, Leicester.

Milioti, D (2000) Nursing Home Literacies, A Journal of Ordinary Literacies, English 348, University of Boston, (an internal course-related document not formally published).

Mission Australia (2007) Grandparents Raising Their Grandchildren, Snapshot Report, Macquarie Bank Foundation, retrieved June 2008 from www.missionaustralia.com.au 
OECD (2000) Literacy in the Information Age: Final Report of the International Adult Literacy Survey, Statistics Canada and OECD.

Office of Communications (2007) Media Literacy Audit: Report on media literacy amongst older people, Ofcom, retrieved June 2008 from www.ofcom.org.uk

Rudd, M (2008) Roll up for the Magical Ancestry Tour, Times online, June 22nd, 2008.

Snyder, I (1997) From Page to Screen, Allen and Unwin, St Leonards, NSW, Australia.

Suarez, D (2007) Grandparents Raising Grandchildren and Heritage Language Maintenance, Presentation to the American Educational Research Association, Chicago Illinois, April 2007.

Weinstein-Shr, G (1995) Literacy and Older Adults in the United States [NCAL Technical Report TR94-17], National Center on Adult Literacy, Philadelphia, PA.

\footnotetext{
${ }^{\mathrm{i}}$ This project was initiated by invitation through the Senior Learners Forum of the Department of Continuing Education at Lancaster University in December 2007. Ten people responded and have participated in the core project, carrying out selfcase studies of changing literacy and technology use. We followed this activity by each conducting two interviews with contrasting members of our families and friends in order to broaden the range of response. The ages of people interviewed to date range from 58-91 years of age.
} 